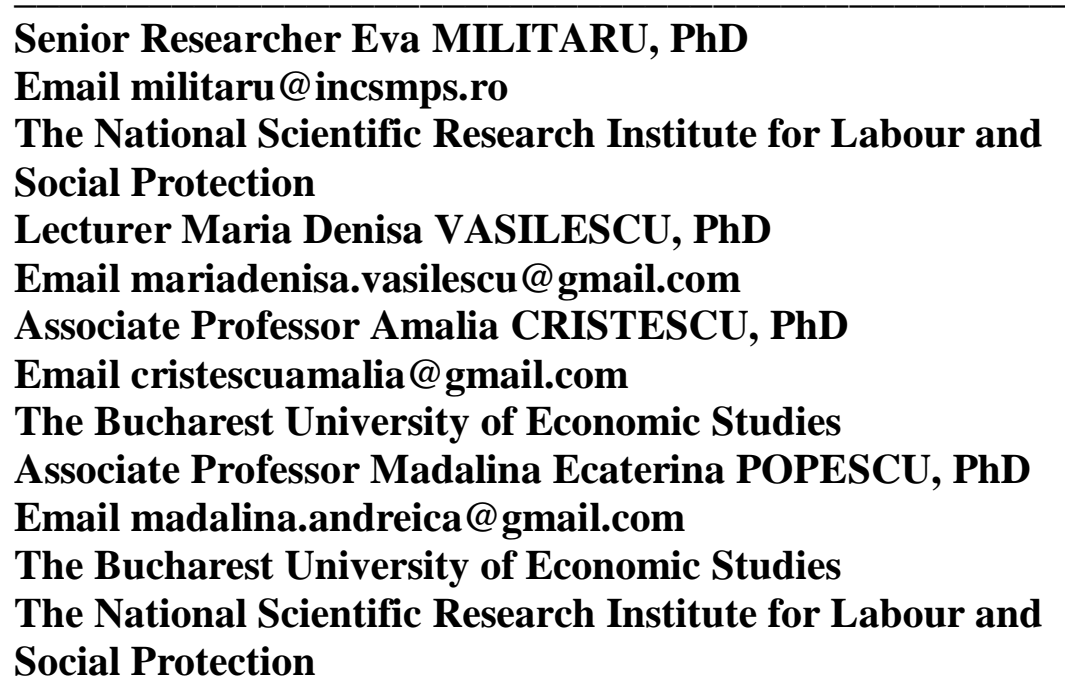

\title{
THE RELATIONSHIP BETWEEN SELF-PERCEIVED HEALTH AND LABOUR MARKET OUTCOMES IN ROMANIA ${ }^{1}$
}

\begin{abstract}
The influence of health status on labour market behaviour is a subject which has benefited of a wide empirical work so far. And the common finding of positive effects of a good health on labour market participation, productivity and wages has been supported by strong evidence. On the other hand, the inverse relationship - the effect of labour market participation on health status -has been less studied. Moreover, the issue has benefited of little attention in Romania. Our paper explores the bidirectional relationship between self-perceived health and labour market outcomes in Romania using a simultaneous equations model. We use EU-SILC data for Romania, the sample being representative for the whole population and consisting of approximately 17 thousand of individuals aged 16 and more. We find that health has a positive influence on labour market participation and incomes, but labour market participation has an adverse effect on health. The results show that individuals do not underreport their health status to justify non-participation. In conclusion, health is endogenous to labour market participation and should be treated as so, otherwise the effects of health on labour market status could be underestimated.
\end{abstract}

Keywords: labour market participation, self-perceived health, incomes, micro econometric modelling

JEL Classification: J21, I10, D01, C13, C51

\footnotetext{
${ }^{1} \mathrm{~A}$ version of this paper was presented at the 12th International Conference on Applied Statistics, 8 June 2018 in Bucharest. We are grateful to the participants for their comments and suggestions.
} 


\section{Introduction}

The impact of health condition on labour market behaviour has been widely studied and debated, and there is a body of international evidence on the effects that the health status of an individual, either objectively measured or selfperceived, has on labour market participation and other outcomes (among others Driouchi and Boboc, 2009; Strauss and Thomas, 1998;Dasgupta, 1997).

Starting from more than fifty years ago, authors such as Schultz (1961), Becker (1964) or Grossman (1972) have explored in theory the relationship between health status and labour market participation, concluding that alongside education, health is the most important determinant of the stock of human capital, being an essential factor for the working decision. Also, they argue that individual preferences between work and leisure can be affected by their health status.

Later on, a large strand of empirical literature has been concerned with the evaluation of the relationship between health status and labour market outcomes and brought strong evidence in favour of the positive effects of a good health condition on labour market participation, productivity and wages (Bradley et al. 2013; Mitchell and Burkhauser, 1990; Stern, 1989; etc.).

What has not yet been studied very extensively, but deserves the same attention, is the inverse relationship, namely the effect of labour market participation on individual health.

In most studies, health status has been treated as exogenous, disregarding the fact that it could be endogenous to labour supply. This is because, on one hand, employment (too many working hours or poor working conditions) can have a negative influence on health, while, on the other hand, non-participation in the labour market could be justified by poor health condition (Stern, 1989; Cai and Kalb 2006; Cai 2010).

Our paper aims at investigating the relationship between self-reported health status and labour market participation, controlling for the endogeneity of the health variable. Also, the effects of health on wages are explored.

Treating health as exogenous in the labour supply estimation, when it is endogenous, would lead to biased estimates (simultaneity bias) and the risks are higher when health is measured subjectively, as it is in our case.

Endogeneity arises because of simultaneity (labour market participation influences health and health influences participation), and could be associated to measurement (self-reported), justification (people tend to justify their labour market status by their health condition) or/and unobserved heterogeneity (unobserved factors that affect both labour market participation and health).

The structure of the paper is the following: Section 2 presents a brief literature review on the topic, while the specific methodology is described inSection 3. Section 4 is dedicated to data set description, while the results of the analysis are presented in Section 5. The conclusions are drawn in the last section. 
The Relationship between Self-perceived Health and Labour Market Outcomes in Romania

\section{Literature review}

One of the most important aspects when analysing health is the measuring issue. We cannot say that there is consensus in the literature regarding the choice of an indicator that best expresses the health of an individual, community, or nation. The concept of health is much more complicated, being in factmultidimensional, according to Ware et al. (1980), and made up of several distinct components to be measured and interpreted separately (Strauss and Thomas, 1998). Over a long period of time, indicators such as height, body mass or body mass index have been used for health status measurements, although they rather reflect nutritional standing. Thomas and Strauss (1997) estimated the separate impact of different health indicators on labour productivity, achieving different outcomes. Another way of measuring health is the self-perceived state of health, in other words a subjective measure. When using such measurement, it is important to bear in mind that a "good" state of health does not mean the same thing for every individual in a community, making it very difficult to establish a reference.

The literature in the field can be divided according to how the relationship between health status and labour market participation is treated, namely: (1) a part of the literature, especially the early one and the most consistent, treats health as an exogenous variable in this relationship, assuming that health status influences labour market participation and other participation-related variables such as income, working time; (2) a much more limited and recent part of the literature treats health as being endogenous in this relationship, i.e. considers that there is a mutual relationship between health and labour-related variables.

Studies that treat health as an exogenous variable have addressed various ways of describing the relationship, using different health indicators. Some of the first models that study the relationship between health and productivity are based on the theoretical models of efficiency wages (Leibenstein, 1957), claiming that the link between nutritional status and labour productivity is positive, but only at inferior levels of nutrition. These models proved to be valid later on, according to Dasgupta (1997), and state that, at least at theoretical level, there should be a positive relationship between health and labour market participation, as well as other labour market outcomes such as wage levels.

Of the studies examining the link between health and work productivity, some use anthropometric measures (height, body mass index) as indicators of health, others take into account indicators of morbidity. These studies highlight a significant relationship between health and work productivity, but the magnitude of this relationship is not clear (Strauss and Thomas, 1998).

Regarding the relationship between health and labour market participation, we note that the health indicators used are even more diverse. Much of the research focuses on the effects that certain illnesses, such as arthritis, cancer or disability, have on the labour market. We can mention Mitchell and Burkhauser (1990), 


\section{Eva Militaru, Maria Vasilescu, AmaliaCristescu, Madalina EcaterinaPopescu}

which analysed the correlation between arthritis and the number of hours worked, as well as the wage level for the working-age population in the United States. They argued the decision of choosing this health indicator by being the most common medical condition in the US and the most common occupational disease. Their results, obtained from the use of two Tobit equations, one for the wage level and one for the number of hours worked, indicate that wages of employees with arthritis were considerably lower than those of employees who did not have this condition.

Other authors such as Bradley et al. (2002) examined the effects of breast cancer on women participation in the US labour market. Based on the Health and Retirement Study (1992) data, they determined that the probability to work registered for women who had this condition in the past was 10 percentage points lower than for healthy women. Thomas and Strauss (1997) estimated the effects of nutrition (with indicators for quantity and quality) on wages in Brazil, and concluded that some of these indicators have significant effects on men's wages, but not on women's wages. Bound et al (1996) analysed the relationship between self-perceived health status and labour market participation in the US and found a significant positive relationship, thus explaining the lower wages of black people compared to white people through their worse health status.

All of the above mentioned studies treat health as an exogenous variable, not considering that it could, and in most cases is endogenous in relation to labour market behaviour, especially throughout the life cycle.

The endogeneity of health in relation to labour market variables has two sources: simultaneity and unobserved heterogeneity, suggesting that the relationship should be approached through a model with simultaneous equations, this being the best solution for obtaining efficient estimates (Cai, 2007). In turn, simultaneity creates two types of endogeneity: real and justification endogeneity. If it was possible to correctly measure the health of an individual, then the endogeneity could be measured with accuracy. However, if the health status is subjective, besides real endogeneity, we also deal with justification endogeneity. Or, in other words, individuals are tempted to justify non-participation on the labour market by a precarious state of health. In this context, using a model in which the health variable is exogenous, the effects on labour market participation could be overstated (Kreider, 1999, Bound, 1991, Anderson and Burkhauser, 1984).

On the other hand, Bazzoli (1985) or Benitez-Silva et al. (2004) state that the subjective indicator of health status is not a problem in relation to the labour market, and Boaz and Muller (1990) showed that people that retire in advance do not underestimate their health to justify retirement. Other authors, such as Kreider (1999), state the opposite, showing that people who are not employed tend to exaggerate their health problems. In order to diminish the justification endogeneity some authors sought to use objective measures for health status, such as morbidity(Anderson and Burkhauser, 1984; Parsons, 1982), or specific diseases (Bound et al., 1999, Campolieti, 2002). 
The Relationship between Self-perceived Health and Labour Market Outcomes in Romania

However, other authors consider that the studies they have carried out do not provide sufficient evidence for the existence of justification endogeneity (Stern, 1989, Cai and Kalb, 2006, Dweyer and Mitchell, 1999). Swaminathan and Lillard (2001) estimated the impact of health on wages and labour market participation based on a latent variable model, and the health status was assessed simultaneously by several indicators in order to control measurement errors. Their results indicate that, after controlling for education and age, no latent health effects on women's wages are observed, but there are significant effects on participation for both sexes. Their conclusions also indicate that the results are sensitive to the health indicator used.

Lee (1982) used a structural equations model to assess the relationship between health and wage levels, and found that both direct and inverse relationships were positive and significant even after correcting the self-perceived health measurement errors. The conclusion was that the two variables are codetermined. Stern (1989) analysed the relationship between health status assessed through the presence/absence of a disability and labour market participation using a system of simultaneous equations. The results indicate that health influences labour market participation, while participation on the labour market does not significantly affect health. The author also identifies two possible sources of endogeneity for health: a direct effect of labour market participation on health (precarious working conditions), or errors in reporting self-perceived health.

A more recent study by Cai and Kalb (2006) follows the same approach as Stern (1989) and uses as health indicator the general state of health, the results converging in the same direction. Cai (2007) provides strong evidence for Australia for rejecting the hypothesis of health exogeneity in relation to labour market behaviour. Using panel data and a simultaneous equations model, he shows that health has a positive influence on labour market participation, while the reverse relationship is positive for women and negative for men.Bidgoli (2017) examines the same link between health status and labour market participation based on a simultaneous equations framework for the period 1996-2010 in the USA. The results clearly indicate the presence of endogeneity, with the relationship between health and labour market participation being positive in both directions.

The other source of endogeneity, the unobserved heterogeneity (Heckman, 1979), arises from the existence of unobservable factors such as attitudes, preferences, motivations that may affect both health and labour market participation.

The conclusion of most studies is that the existence of health endogeneity in relation to the labour market is nevertheless very probable and any analysis should take this into account. 


\section{The methodology}

In order to study the influence of health condition on labour market we employ a simultaneous equation modelling framework similar to other studies (Bidgoli, 2017;Cai, 2010; Cai and Kalb, 2006; Stern, 1989).Our model is based on the following equations:

where

$$
\begin{aligned}
& h_{i}^{* *}=\propto l_{i}^{*}+\beta X_{i}+\varepsilon_{1 i} \\
& l_{i}^{*}=\gamma h_{i}^{* *}+\varphi Y_{i}+\varepsilon_{2 i} \\
& h_{i}^{*}=h_{i}^{* *}+\omega l_{i}^{*}+\varepsilon_{3 i}
\end{aligned}
$$

eq. (1) is the health equation, with $h_{i}^{* *}$ being the latent true health, depending on the also latent value of labour market status $l_{i}^{*}$ (latent variables were used because of the health endogeneity hypothesis) and on a set of $X$ exogenous variables influencing true health. The coefficient $\propto$ denotes true endogeneity.

eq. (2) is the labour participation equation, with $l_{i}^{*}$ and $h_{i}^{* *}$ as above and $\mathrm{Y}$ a set of exogenous variables influencing labour participation ( $\mathrm{X}$ and $\mathrm{Y}$ could have common variables). The coefficient $\omega$ denotes justification endogeneity.

eq. (3) is the relationship between true health $h_{i}^{* *}$ and self-reported health $h_{i}^{*}$, as true health is not being observed.

Because of the unobserved true health, we have to substitute (1) in (3) and estimate the following equation instead:

$$
h_{i}^{*}=\rho l_{i}^{*}+\beta X_{i}+\varepsilon_{4 i}
$$

where $\rho=\propto+\omega$, is the total endogeneity which can be estimated. Even though its components - true and justification endogeneity cannot be identified, their signs can and will be discussed.

Next, we extract $h_{i}^{* *}$ from (3) obtaining $h_{i}^{* *}=h_{i}^{*}-\omega l_{i}^{*}-\varepsilon_{3 i}$ and substitute it in (2). The following equation results:

where $\gamma_{1}=\frac{\gamma}{1-\gamma * \omega}$

$$
l_{i}^{*}=\gamma_{1} h_{i}^{*}+\varphi Y_{i}+\varepsilon_{5 i}
$$

The health status was assessed through a discreet variable that subjectively measures general self-perceived health on a scale from 0 (very bad) to 4 (very good). The transformation of the observed variable into a latent one is performed as described below:

$$
h_{i}=\left\{\begin{array}{c}
=4(\text { very good }), m_{4}<h_{i}^{*}<+\infty \\
=3(\text { good }), m_{3}<h_{i}^{*} \leq m_{4} \\
=2(\text { fair }), m_{2}<h_{i}^{*} \leq m_{3} \\
=1(\text { bad }), m_{1}<h_{i}^{*} \leq m_{2} \\
=0(\text { very bad }), \quad-\infty<h_{i}^{*} \leq m_{1}
\end{array}\right\}
$$


The Relationship between Self-perceived Health and Labour Market Outcomes in Romania

where $h_{i}$ is the the self-perceived health status and $m_{1}, \ldots m_{4}$ will also be estimated.

$$
l_{i}=\left\{\begin{array}{c}
=1(\text { in labour force }), l_{i}^{*}>0 \\
=0(\text { not in labour force }), l_{i}^{*} \leq 0
\end{array}\right\}
$$

where $l_{i}$ is the labour market status.

The parameters are estimated through the maximum likelihood estimation method (MLE) using conditional mixed-process (CMP) framework.

We do the estimations separately for men and women using the cmp command implemented in STATA by Roodman (2011) in order to jointly estimate the equations with linkages between their error processes.

\section{Data}

The microdata we use is cross-sectional data from the 2015 EU-SILC (European Union Survey on Income and Living Conditions) for Romania, the sample being representative for the whole population and consisting of approximately 17 thousand individuals aged 16 and over. The survey collects information on demographic variables, labour market, health and education. Health measurement is subjective -self-perceived general health: how a person perceives his/her health in general, ranked from very good to very bad. Self-reported general health is an indicator of personal health that reflects both health status and health expectations, indicating to a certain level the general quality of life. Socioeconomic traits, such as educational level, occupational status, income level, gender and age are important factors contributing to the differentiated assessment of own health status.

As it can be seen below (Table 1), labour market status by self-reported health of working-age population shows that better health is associated with participation on the labour market. Thus, almost all of the individuals who assessed their health condition as being very good were participating in the labour market. Conversely, the majority of those who felt in a bad or very bad general health state were out of the labour force.

Table 1. Self-reported general health of working-age population according to labour market status, \%

\begin{tabular}{|c|c|c|c|c|c|}
\hline & $\begin{array}{l}\text { very } \\
\text { good }\end{array}$ & good & fair & bad & $\begin{array}{l}\text { very } \\
\text { bad }\end{array}$ \\
\hline Females & & & & & \\
\hline labour force non- participation & 5.2 & 3.5 & 7.1 & 34.8 & 68.9 \\
\hline $\begin{array}{c}\text { participation in labour force } \\
\text { Males }\end{array}$ & 94.8 & 96.5 & 92.9 & 65.3 & 31.1 \\
\hline
\end{tabular}


Eva Militaru, Maria Vasilescu, AmaliaCristescu, Madalina EcaterinaPopescu

\begin{tabular}{crrrrr}
\hline labour force non- participation & 8.4 & 7.6 & 10.9 & 58.7 & 71.1 \\
participation in labour force & 91.6 & 92.4 & 89.2 & 41.3 & 28.9 \\
\hline
\end{tabular}

Source: Authors' own calculations based on 2015 EU-SILC data.

Primarily, this situation can be explained by the fact that persons who participate in the labour market are generally healthy people, able to work. Secondly, we can consider that people who participate in the labour market earn a certain income that enables and facilitates their access to medical services, by which they can improve their health. On the other hand, people who participate in the labour market are required to periodical medical checks according to the work they carry out, and thus prevention can play an important role for a better health. Moreover, labour market participation can have a positive influence on a person's health, including through the facilitation of social status, utility, interactions with different people and situations, etc. We can say that the relationship between health and labour market participation indicates a mutual influence.

Among socio-demographic features, age is the most important predictor of general health status. In our sample, over $90 \%$ of people up to 44 years old assessed themselves as being in a good and very good health, while only $50 \%$ of the people aged between 55-64 years did the same (see Table 2). And this is relevant in the context of health and labour market policy development for an aging population. Also, we mention that around 90\% of people aged 25-64 years were in the labour force, as employed or unemployed, while less than $75 \%$ of people aged 15-24 years were participating on the labour market.

We find gender differences in self-perceived health, men being more appreciative to their health condition than women. According to our data, $75 \%$ of men and $65 \%$ of women assess their own health as being good or very good (see Table 2). We can explain the results either by the fact that women may be more concerned about their true health and more objective in assessing it, or their health status is indeed worse than men's, bearing in mind that pregnancy, raising children and household responsibilities can have a negative influence on women's health status, or both.

As it is shown below, as the level of education improves, the perception regarding a good and very good health increases as well. Thus, we can say that the educational level is an important factor influencing lifestyle and risk awareness, and more educated people are better assessing their health. Clearly, people with higher education also have better paid jobs, and economic resources enable them to take care of their health and access more easily health services and information, but at the same time, they also allow themselves to adopt a more healthy and preventive lifestyle. 
The Relationship between Self-perceived Health and Labour Market Outcomes in Romania

Table 2. Self-reported general health of working age population, by sociodemographic characteristics, \%

\begin{tabular}{lrrrrr}
\hline Age group & very good & good & fair & bad & very bad \\
15-24 years & 75.6 & 23.2 & 0.6 & 0.2 & 0.5 \\
25-34 years & 49.6 & 46.0 & 3.2 & 0.5 & 0.6 \\
35-44 years & 31.4 & 60.6 & 6.8 & 0.9 & 0.3 \\
45-54 years & 15.8 & 62.5 & 16.7 & 4.0 & 1.1 \\
55-64 years & 4.2 & 45.6 & 37.7 & 10.7 & 1.8 \\
Education & & & & & \\
Not completed & 22.4 & 23.0 & 20.2 & 19.3 & 15.2 \\
primary education & & & & & \\
Primary & 7.7 & 25.7 & 38.1 & 24.0 & 4.5 \\
Lower Secondary & 24.8 & 40.9 & 25.2 & 7.9 & 1.2 \\
Upper Secondary & 29.3 & 47.1 & 17.8 & 4.9 & 1.0 \\
Post-Secondary & 21.4 & 47.5 & 24.6 & 4.6 & 2.0 \\
Tertiary & 36.8 & 48.9 & 12.1 & 1.7 & 0.5 \\
Gender & & & & & \\
Females & 23.4 & 41.9 & 24.4 & 8.8 & 1.6 \\
Males & 30.1 & 44.8 & 18.6 & 5.3 & 1.3 \\
All & 26.6 & 43.3 & 21.6 & 7.1 & 1.4 \\
\hline \multicolumn{2}{l}{ Source:Authors }
\end{tabular}

Source: Authors' own calculations based on 2015 EU-SILC data.

\section{Results and discussion}

Table 3 shows the coefficient estimates for the simultaneous equation models, separately for men and women. We start by discussing the influence of health condition on labour market status. The coefficient of the health status variable is positive in the labour market participation equation, indicating that better health condition improves the chances of labour market participation both for men and women, the relationship being stronger for the former. These results confirm the findings of other similar researches. But, besides health condition, labour market participation is also influenced by age (possible proxy for work experience) and the relationship has a quadratic form, suggesting that to a certain age the link is positive, while when becoming elder, even still in working age, the chances of labour market participation are lower. Moreover, we estimate significant effects of geographical area on labour market participation, as there are better employment opportunities in certain regions. And we mention the influence of marital status 
Eva Militaru, Maria Vasilescu, AmaliaCristescu, Madalina EcaterinaPopescu

especially in the case of men - being married is a significant predictor of labour force participation.

Examining the second equation which describes the reversed relationship between health and labour market participation, it seems clear that labour market participation has a negative impact on health, both for men and women, but stronger for women. Other variables that influence general health status are age, income level, chronic illness, long-standing limitation in activities, unmet need for medical examination or treatment, education and assets ownership. The signs of the variables are as expected. To detail, our results show that age has a negative effect on general health condition, as well as the presence of chronic illness or long-standing limitation in activities, in a similar manner for both genders. On the other hand, examining the relationship between disposable income and health condition, we find that poorer individuals seem to have a worse health condition, compared to individuals in higher income strata. In the case of men, this effect is being stronger. Owning assets such as computers, which could also be regarded as a proxy for access to information has a positive influence on males' health, while the number of rooms in the dwelling is also a predictor of better health, especially for women. For the latter as well, the number of children taken care of is significant and has a negative effect on their health condition. At last, but not least, higher education is significant and thus, better education has positive influence on health condition.

Table 3.Coefficient estimates for the simultaneous equations model

\begin{tabular}{lcc}
\hline & Females & Males \\
labour market participation equation & & \\
health status & 0.4879 & 0.5683 \\
married & $0.1698^{*}$ & 0.4932 \\
divorced & & 0.3240 \\
widowed & & 0.7821 \\
age & 0.1636 & 0.0917 \\
squared age & -0.0013 & -0.0005 \\
macroregion 1 (NW, C) & 0.3740 & 0.5712 \\
macroregion 2 (NE, SE) & 0.3087 & 0.1680 \\
constant & -2.3868 & -1.5114 \\
health equation & & \\
labour market participation (0 - non participation, 1 & & \\
participation) & $-0.1832 *$ & $-0.0786^{*}$ \\
suffer from chronic illness (1-yes, 0-no) & -0.8922 & -0.8084 \\
long-standing limitation in activities (1-yes, 0-no) & -2.2736 & -1.7366 \\
unmet need for medical examination or treatment (1-yes, 0-no) & -0.3895 & -0.3160 \\
unmet need for dental examination or treatment (1-yes, 0-no) & -0.3018 & -0.1492 \\
urban area (1-yes, 0-no) & -0.1882 & -0.1721 \\
\hline
\end{tabular}


The Relationship between Self-perceived Health and Labour Market Outcomes in Romania

\begin{tabular}{lcc}
\hline number of dependent children & $-0.0390^{*}$ & \\
presence of a disability (1-yes, 0-no) & -2.0943 & -1.5962 \\
post-secondary education (1-yes, 0-no) & $0.1939^{*}$ & \\
tertiary education (1-yes, 0-no) & 0.2395 & \\
age & -0.0426 & -0.0444 \\
log of disposable income & 0.1343 & 0.1699 \\
number of rooms of the dwelling & 0.0661 & 0.0487 \\
computer ownership & & 0.1172 \\
Coorelation coefficient of errors & -0.3374 & -0.5402 \\
\hline
\end{tabular}

* Significant at $10 \%$, all other estimations are significant at $5 \%$.

To sum up, the results shown in Table 3 indicate that health influences labour market participation, while at the same time, labour market participation affects health condition. The results are to some extent similar for men and women, the coefficients' signs are the same, only their sizes differ. Also, some variables prove to be significant only for males or only for females.

Now, going back to the coefficient of labour market participation in the health equation, we have to point out several aspects in correlation with the methodological approach described in section 3 of this paper. The negative sign of the coefficient shows that the combined effect of true and justification endogeneity is negative, both for males and females. Because the justification endogeneity generally tends to be positive, as the labour market status should have a positive effect on self-perceived health (Cai and Kalb 2006; Cai 2010), the below zero estimates for the labour market participation variable show that even if justification endogeneity exists, it is less significant than the negative effects resulting from the true endogeneity. These would mean that people do not have the tendency to under report their health condition as an explanation for not being activeon the labour market.

Given the results above, and added the fact that the errors correlation coefficients are significant at all levels, we could conclude that including health in the labour participation equation as an exogenous variable would not be a correct option. In other words, health is endogenous in the relationship with labour market participation. Our results are generally in line with other empirical researches in the field, such as Cai (2007) or Bidgoli (2017), in what concerns proving the presence of endogeneity in the relationship. Still, they are different to the extent that the justification endogeneity could not be totally rejected in the case of women in Cai (2007), or for both genders in Bidgoli (2017) as a result of positive coefficients of labour market participation in the health equation.

We further developed our analysis by estimating the influence of health on other labour market outcomes. In this context, we explored the relationship between health status and wages, controlling for self-selection into employment 
Eva Militaru, Maria Vasilescu, AmaliaCristescu, Madalina EcaterinaPopescu

(Heckman, 1979).The results are shown in Table 4.Mainly, they indicate that those who have negative perceptions about their general health condition have lower wages on average compared to those who are satisfied with their health. Same finding applies for men and women as well. Other variables such as occupation, economic activity, age, education, region, etc. influence as expected the level of wages, the power of the links and the signs varying between males and females.

Table 4.Coefficient estimates for log wage equation

\begin{tabular}{lcc}
\hline & Females & Males \\
health status & 0.0352 & 0.0353 \\
age & 0.0597 & 0.0772 \\
squared age & -0.0007 & -0.0008 \\
post-secondary education & & 0.2337 \\
tertiary education & 0.1824 & 0.2674 \\
urban area & 0.1186 & 0.1003 \\
macroregion 1 (NW, C) & 0.0952 & 0.1433 \\
macroregion 2 (NE, SE) & -0.1111 & \\
occupation: senior officials and managers & 0.5735 & 0.4241 \\
occupation: professionals & 0.4851 & 0.3573 \\
occupation: technicians and associate professionals & 0.3519 & 0.2282 \\
occupation: clerks & 0.2011 & 0.1697 \\
occupation: service and sales workers & 0.0800 & \\
occupation: skilled agricultural & -0.3390 & -0.7423 \\
occupation: craft and trades workers & & 0.0875 \\
economic activity: Agriculture and Fishing & -1.5612 & -0.6642 \\
economic activity: Mining, Manufacturing and Utilities & & 0.1631 \\
economic activity: Wholesale and retail trade & -0.1184 & 0.1168 \\
economic activity: Hotels and restaurants & & 0.1521 \\
economic activity: Transport and communication & & 0.2096 \\
economic activity: Public administration and defence & & 0.2584 \\
economic activity: Education & -0.2187 & \\
economic activity: Health and social work & -0.0969 & \\
\hline
\end{tabular}

\section{Conclusions}

This paper has focused on the estimation of the relationship between selfreported health status and labour market participation, by using a simultaneous equations model framework and paying attention in particular to the endogeneity of health. In addition, we have explored the effects of health on wage levels, controlling for self-selection into employment. Using EU-SILC data for Romania, our results confirm the common finding in relevant literature according to which health condition has a positive influence on labour market participation. These findings are valid both for males and females. 
The Relationship between Self-perceived Health and Labour Market Outcomes in Romania

Other consistent finding emerging from our analyses is that the reverse effect, namely labour market participation on health, is also significant and negative for both genders. It suggests that labour market participation has an adverse effect on health. Moreover, judging by the sign of the coefficient and considering that labour market status in general has a positive effect on self-reported health status, we could conclude that the justification endogeneity hypothesis can be rejected. It means that individuals do not under report their health status to justify nonparticipation on the labour market.

The above findings together with the significant correlation of errors, lead us to the conclusion that health is endogenous to labour market participation and should be treated as so, otherwise the effects of health on labour market status could be underestimated.

Throughout our analyses we have identified a range of variables which influence labour market participation or health status. Among them we mention age for both, marital status and region for labour market participation, chronic illness, education, number of dependent children and assets ownership for health status.

Health status is also significant for the wage level of working individuals, a better health condition being associated with higher wages.

Some caveats should be mentioned though. First, due to availability reasons, our data is cross-sectional. We believe that more relevant results could have been obtained with the use of panel data. Second, our measure of health status is selfreported. Being a subjective measure itis likely to be strongly connected with individual socio-demographic characteristics. Also, it can be affected by systematic measurement errors. Moreover, from the relevant literature in this field it is not clear yet how the use of subjective health measures influences the outcomes of labour supply models.

To conclude, we consider that exploring the relationship between health status and labour market outcomes in Romania is important also for policy making. For a country with poor health indicators and low participation of elderly in the labour force as compared to other EU countries, any investment in healthwould have considerable economic consequences. Future research should focus on the longitudinal, life-cycle perspective and the role of education in shaping the relationship between health and labour market participation.

\section{REFERENCES}

[1] Anderson, K.H., Burkhauser, R.V. (1984), The Importance of the Measure of Health in Empirical Estimates of the Labour Supply of Older Men; Economics Letter 16: 375-380;

[2] Bazzoli, G.J. (1985), The Early Retirement Decision: New Empirical Evidence on the Influence of Health; Journal of Human Resources 20: 214 234; 
Eva Militaru, Maria Vasilescu, AmaliaCristescu, Madalina EcaterinaPopescu

[3] Becker, G.S. (1964),Human Capital. New York, Columbia University Press;

[4] Benitez-Silva, H., Buchinsky, M., Chan, H.M., Cheidvasser, S., Rust, J. (2004),How Large is the Bias in Self-assessed Disability?; Journal of Applied Econometrics 19: 649-670;

[5] Boaz, R.F., Muller, C.F. (1990),The Validity of Health Limitations as a Reason for Deciding to Retire; Health Services Research 25(2): 361-386;

[6] Bound, J. (1991), Self-reported versus Objective Measures of Health in Retirement Models; Journal of Human Resources 26(1): 106-138;

[7] Bound, J., Schoenbaum, M., Waidmann, T. (1996), Race Difference in Labor Force Attachment and Disability Status; The Gerontologist 36(3): 311-321;

[8] Bound, J., Schoenbaum, M. and Waidmann, T. (1999), The Dynamic Effects of Health on the Labor Force Transitions of Older Workers; Labour Economics 6:179-202;

[9] Bradley, C., Bednarek, H., Neumark, D. (2002),Breast Cancer and Women's Labor Supply; Health Services Research, 37(5): 1309-1327;

[10] Bradley, C., Neumark, D., Barkowski, S. (2013),Does Employer-provided Health Insurance Constrain Labor Supply Adjustments to Health Shocks? New Evidence on Women Diagnosed with Breast Cancer; Journal of Health Economics, 32(5): 833-849;

[11] Cai, L. (2010),The Relationship between Health and Labour Force Participation: Evidence from a Panel Data Simultaneous Equation Model; Labour Economics, 17(1): 77-90;

[12] Cai, L., Kalb, G. (2006),Health Status and Labour Force Participation: Evidence from Australia; Health Economics, 15: 241-261;

[13] Cai, L (2007), The Relationship between Health and Labour Force Participation: Evidence from a Panel Data Simultaneous Equation Model; Melbourne Institute Working Paper No. 1/07;

[14] Campolieti, M. (2002), Disability and the Labor Force Participation of Older Men in Canada; Labour Economics 9: 405-432;

[15] Dasgupta, P. (1997), Nutritional Status, the Capacity for Work and Poverty Traps; Journal of Econometrics, 77 (1): 5-37;

[16] Driouchi, A., Boboc, C. (2009),Do Better Health and Education Enhance Economic Development?; Economic Computation and Economic Cybernetics Studies and Research; Faculty of Economic Cybernetics, Statistics and Informatics, 43(3): 189-204;

[17] Dwyer, D.S., Mitchell, O.S. (1999),Health Problems as Determinants of Retirement: Are Self-Rated Measures Endogenous?; Journal of Health Economics 18: 173-193;

[18] Grossman, M. (1972), On the Concept of Health Capital and the Demand for Health; Journal of Political Economy 80: 223-255;

[19] Heckman, J. (1979), Sample Selection Bias as a Specification Error; Econometrica, 47.1:153-161; 
The Relationship between Self-perceived Health and Labour Market Outcomes in Romania

[20] JafariBidgoli, M. (2017), Essays on Health and Labor Market Outcomes; Wayne State University Dissertations. 1813, https://digitalcommons.wayne.edu/oa_dissertations/1813;

[21] Kreider, B. (1999), Latent Work Disability and Reporting Bias; Journal of Human Resources 34(4): 734-769;

[22] Lee, L.F., (1982), Health and Wage: A Simultaneous Equation Model with Multiple Discrete Indicators. International Economic Review 23 (1): 199221;

[23] Leibenstein, H. (1957), Economic Backwardness and Economic Growth: Studies in the Theory of Economic Development; New York: Wiley \& Sons;

[24] Mitchell, J., Burkhauser, R. (1990),Disentangling the Effect of Arthritis on Earnings: A Simultaneous Estimate of Wage Rates and Hours Worked; Applied Economics 22(10):1291-1309;

[25] Parsons, D.O. (1982), The Male Labour Force Participation Decision: Health, Reported Health and Economic Incentives; Economica49(193): 81-91;

[26] Roodman, D. (2011), Estimating Fully Observed Recursive Mixed-Process Models With cmp; Stata Journal 11(2): 159-206;

[27] Schultz, T.W. (1961), Investment in Human Capital; American Economic Review, 51: 1-17;

[28] Stern, S. (1989), Measuring the Effect of Disability on Labour Force Participation; Journal of Human Resources 24(3): 361-395;

[29] Strauss, J., Thomas, D. (1998),Health, Nutrition and Economic Development; Journal of Economic Literature. Volume 36 (2);

[30] Swaminathan S, Lillard L. (2000), Health and Labor Market Outcomes: Evidence from Indonesia; Mimeo, University of Michigan;

[31] Thomas, D., Strauss, J. (1997), Health, Wealth and Wages of Men and Women in Urban Brazil; Journal of Econometrics 77: 159 - 185;

[32] Ware,J., Allyson,D., Robert,B. (1980),Conceptualization and Measurement of Health Status for Adults, in Health Insurance Study: Vol. VI. Analysis of relationships among health status measures, R-1987/6-HEW, RAND, Santa Monica, CA; 